REVIEW

\title{
The plot thickens
}

\section{Cutting for Stone}

Abraham Verghese

Random House of Canada Ltd.; 2009.

560 pp $\$ 26.95$

\section{A braham Verghese's novel Cutting for Stone recounts the story of Marion Praise} Stone's journey from before his birth, at a mission hospital in Ethiopia, to his surgical practice in the United States. The book contains some very fine prose and among its satisfactions - it is clearly meant to appeal to a medical readership — is its vivid description of medical practice in Africa and the dedication of the people who devote their lives to such work.

The story is narrated by Marion, who is one half of conjoined twins born to an Indian nursing sister and fathered by Thomas Stone, a supremely skilled surgeon who nonetheless botches their delivery (rendering them motherless) before fleeing the scene. The twin boys, who were separated after birth, are taken in by 2 other doctors at the mission.

It is during this opening act that we are also treated to a detailed story of Thomas Stone's deliberate self-amputation of his finger, leaving the digit to bob, suggestively, symbolically, in a jar of formalin. This whirlwind is a prelude to a veritable compendium of plot twists - a near plane crash, a coup, a hijacking, etc. - and as much as I appreciated Verghese's efforts, I did begin to find the multiplying implausibilities distracting, a paradox of a plot so exuberant it began to obscure Marion's story.

The book's middle section, which recounts the twins' childhood in the mission hospital, is told more simply, and I felt the story was better served for it. The true strength of this novel (and a promise of what it could have been) resides here; stripped of the cartwheeling

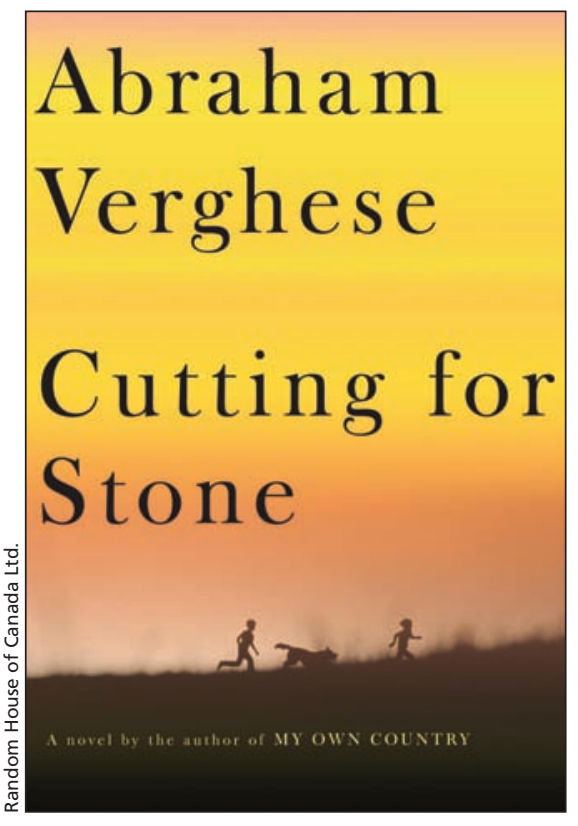

plot machinations of the opening act, Verghese's storytelling simplifies and intensifies, thus the characters escape the harness of caricature, vivifying more for their psychological complexity rather than because of far-fetched circumstance.

It is in this part of the book that the most satisfyingly realized character, Marion's adoptive father, Ghosh, emerges. Ghosh doesn't last long, however, and the plot revs up again, spiriting Marion (who has been falsely implicated as a terrorist) to New York City, New York, for a surgical residency. Here, a matrix of too-tidy coincidences takes shape, reuniting him with his estranged, 9-fingered surgeon father and his terrorist commando/ unrequited first love, Genet.

It disappointed me that by the book's end I felt as though Marion's motivations were still largely unexplored. One could argue that this was simply the author's desire for ambiguity, but in a book as committed to obsessive detail as this one, for the main character to lack depth is a very telling shortcoming. Why does Marion want to be a surgeon? (Especially given that in doing so he is emulating the father who abandoned him and had a hand in his mother's death). Why would such a man as Marion remain a virgin well into his 30s, ostensibly saving himself for his childhood sweetheart, whom he may never see again, a woman who betrayed him and whom he now clearly loathes? It is certainly possible, but Marion's character is never developed enough to address this conflict - a conflict that one imagines would occupy, if not dominate, at least some of the inner life of most people. We see so little in the way of inner turmoil in Marion that when he finally confronts Thomas Stone and, especially, Genet, both his anger and his passion are unconvincing.

"The worst part is I still loved her." This is the best explanation we are given for Marion's actions regarding his first love. Instead of character development we get a bleat of adolescent mooning. In a book where no plot twist is too implausible to be indulged, where twins are conjoined and every meeting is graced by fate, where even a severed digit is endowed with the dignity of a story, "I still loved her" is just not enough. The most telling criticism is that after more than 500 pages of Cutting for Stone, I understood more about Thomas Stone's amputated finger sitting in a jar of formalin than I knew about the protagonist's head or his heart.

\section{Liam Durcan MD}

Neurologist

Montreal Neurological Hospital Montréal, Que.

Dr. Durcan is the author of 2 books of fiction, Garcia's Heart (2007) and A Short Journey by Car (2004). He is currently working on his next novel. 